\title{
Modelling the third dimension: incorporating topography into the movement rules of an individual- based spatially explicit population model
}

\author{
J. Alderman ${ }^{1}$, S.A. Hinsley ${ }^{2}$ \\ ${ }^{1}$ Landscape and Biodiversity Research Group, School of Applied Sciences, University of \\ Northampton, Park Campus, Northampton, NN2 7AL, UK. email: jolyon.alderman@btinternet.com \\ ${ }^{2}$ Centre for Ecology and Hydrology, Monks Wood, Abbots Ripton, Huntingdon, Cambridgeshire, \\ PE28 2LS, UK. email: sahi@,ceh.ac.uk
}

Correspondence address: Dr. J Alderman, 2 Friars Avenue, Delapre, Northampton, Northamptonshire, NN4 8PY, UK. email: jolyon.alderman@btinternet.com

\begin{abstract}
A wide variety of topographical and environmental elements have been shown or proposed to influence the movement decisions of dispersing animals. Most real landscapes have topographical elements such as hills, valleys and urban developments, which can all act to modify a species' perceptual range and directly influence movement behaviour. If a visual-based perceptual ability enables a dispersing individual to locate suitable habitat patches at a distance, then it is to be expected that topographical features would act to modify the overall success of this strategy. However, the majority of individual-based Spatially Explicit Population Models (SEPM) employ only two-dimensional landscapes.
\end{abstract}

To investigate the effects of topographical elevation on dispersal patterns, a threedimensional visual-based perceptual range algorithm was added to the dispersal rules of an individual-based SEPM. To explore the possible influences of a behaviouralbased response to topography, an algorithm modelling valley-seeking behaviour was also developed. The performance of both algorithms was compared with that of a twodimensional visual-based perceptual range algorithm. The overall consequences of 
dispersal under each algorithm were measured by recording population sizes in a target wood in the centre of a modelled, real landscape.

The size of the population in the target wood, modelled using both of the threedimensional algorithms, exhibited sensitivity to the direction of dispersal in interaction with perceptual range, which differed from that predicted by the twodimensional approach. Population size was dependant on the spatial configuration of habitat patches and on the topography of the landscape, both of which could guide dispersers either towards or away from the target patch depending on the particular combinations of dispersal directions and perceptual ranges selected. Topography was found to have a greater effect on dispersal at shorter perceptual ranges, and thresholds in the results for all three algorithms suggested the existence of species and landscape dependant optimal perceptual ranges. It is recommended that both topography and topographical-based dispersal-altering algorithms, commensurate with the studied species' behaviour, be incorporated into the movement rule-base of dispersal simulation models. The modelling of topography and its effects on movement in patchy landscapes are seen as essential ingredients in future landscape planning.

\section{Keywords}

Elevation, dispersal, PatchMapper, perceptual range, SEPM, topography

\section{Introduction}

One of the effects of habitat fragmentation is to isolate species in separate habitat patches, with dispersal between the patches requiring individuals to traverse unsuitable and often inhospitable parts of the landscape, often referred to as 'the matrix' (Andren, 1994; Fahrig, 1997; Haydon and Pianka, 1999; Zollner and Lima, 1999; Ricketts, 2001; Fahrig, 2003). The degree to which a particular dispersing species is successful in locating fragmented habitat is dependent, in part, on the physical characteristics of the species and its behavioural responses to the various 
landscape elements (Alderman et al., 2005). The resulting inter-patch movements result in species-dependant dispersal-flow patterns linking the various patches within a landscape (Alderman, 2005).

A wide variety of topographical and environmental elements have been either shown or proposed to influence the movement decisions of dispersing animals (Gustafson and Gardner, 1996; Roland et al., 2000; Tischendorf and Fahrig, 2000; Tuck and Hassall, 2004; Pe'er et al., 2005; Kindlmann et al., 2005). Individuals of particular species have also been shown to vary their search strategies in response to their immediately perceived surroundings (Zollner and Lima, 2005; Heinz and Strand, 2006). Aside from environmental cues, such as wind, precipitation, magnetic fields and polarised light (Yeomans, 1995; Acevedo et al., 2005; Schooley and Branch, 2005), animals may also respond to various topographical-based elements. These include the influence of slope aspect and gradient on the migration patterns of red deer (Cervus elaphus) (Mysterud et al., 2001), the hill-climbing behaviour of the lesser spotted fritillary (Melitaea trivia) (Pe'er et al., 2004) and a preference of the African elephant (Loxodonta africana) for level ground (Wall et al., 2006).

Early definitions of the distance over which a particular species is able to distinguish between different landscape elements include its 'radius of detection', 'reactive distance' or 'detection distance' (Cain, 1985; Fahrig, 1988; Adler and Nuernberger, 1994). More recently, the concept has become referred to as 'perceptual range'. An individual species' visual perceptual range defines the areal extent of the landscape over which individuals of that species can make visual distinctions between different landscape elements (Zollner and Lima, 1997; Zollner, 2000). The detected landscape elements can be used by an individual as basic information on which to formulate its movement choices (Olden et al., 2004). Perceptual range can therefore be expected to influence the population sizes in individual habitat patches and the distribution of a population throughout a particular landscape. For a dispersing individual, a reduction of its perceptual range results in less of the landscape being 'seen'. This in turn increases the time spent in the matrix before locating a habitat patch, thereby increasing the chance of dispersal mortality through factors such as reserve depletion and predation (Lima and Zollner, 1996; Schooley and Wiens, 2003). 
The concept of visual-perceptual range, viewed as a functional trait of an individual species moving within its environment, can also be considered as a component of the 'eco-field' paradigm proposed by Farina and Belgrano (2004). Within this paradigm, visual-based perceptual range would form an emergent property of a multidimensional landscape, creating a 'view' of the landscape within the cognitive space of the dispersing individual, contributing to that individual's overall perception of the landscape.

Most landscapes are not two-dimensional and incorporate topographical heterogeneity to varying degrees (Pe'er et al., 2006). If a visual-based perceptual ability enables a dispersing individual to locate suitable habitat patches at a distance, then it is to be expected that topographical features would act to modify the overall success of this strategy. Hills could, for example, act to obscure the view of potentially suitable habitat (Fig. 1). Valleys could act as corridors, guiding a disperser towards or away from potentially suitable habitat. Determining the dispersal-flow paths of individuals that use visual-based perceptual range, in a two-dimensional representation of a topographically rich landscape, is likely to give misleading results. There is a distinct possibility of predicting false dispersal paths and incorrectly estimating the population sizes in target patches. Depending on the relative positions of disperser, topographical feature and habitat patch, determining the dispersal flow paths in a three-dimensional representation of the same landscape should more accurately describe the complexity of the response of the disperser to a real landscape and thus give more dependable results.

This study describes a three-dimensional visual-based perceptual range algorithm, which, when added to the dispersal rules of an individual-based Spatially Explicit Population Model (SEPM), enables the elevation of a landscape to influence interpatch dispersal paths. To explore the additional benefits of modelling elevation, the model was further enhanced by the addition of a behavioural-based topographical response, in the form of a valley-seeking algorithm. The performance of both algorithms was compared with that of a two-dimensional visual-based perceptual range algorithm, by recording their respective effects on dispersal paths through a landscape of fragmented habitat patches. The overall consequences of dispersal under 
each algorithm were measured by recording population size in a target wood in the centre of the modelled landscape.

Within north-western European agricultural landscapes, woodland is highly fragmented and exists largely as scattered patches (Pain and Pienkowski, 1997, Hinsley et al., 1998, Benton et al., 2003). In such landscapes, territorial woodland species are forced to disperse between patches, with dispersal occurring on a landscape scale (Saïd and Servanty, 2005). The nuthatch (Sitta europaea) is an example of a residential, univoltine territorial woodland species, which is known to disperse from the natal patch in search of suitable breeding habitat (Nilsson, 1987; Pravosudov, 1993; Matthysen et al., 1995; Matthysen and Currie, 1996). It has been found that univoltine territorial species are ideal for modelling with individual based SEPMs (Alderman, J., 2005) and, allied to the availability of landscape and nuthatch habitat occupancy data, it was decided to base this study on the dispersal of nuthatches within an agricultural landscape in eastern England. This landscape is dominated by intensive arable agriculture within which woodland is relatively scarce (c. $3 \%$ of land cover) and about $50 \%$ occurs in patches of 10 ha or less (Forestry Commission 1980, unpubl.) The overall consequences of dispersal under each algorithm were measured by recording population size in a target wood (Monks Wood) in the centre of the modelled landscape.

\section{Methods}

\subsection{Model Species and Study Area}

The nuthatch is a small (c. 21-23 g) cavity-nesting woodland passerine (Matthysen and Adriaensen, 1998), resident in the UK. The nuthatch is noted as being sensitive to isolation (e.g. Enoksson et al., 1995; Hinsley et al., 1995; Matthysen et al., 1995; Bellamy et al., 1998), suggesting that perceptual range may play a part in the viability of nuthatch populations in fragmented landscapes. Previous work (Bellamy et al., 1998; Alderman, 2005; Alderman et al., 2005) has indicated that the fragmented nature of woodland in the study area and its effects on nuthatch dispersal play an important role in the scarcity and distribution of the species in this landscape. 
The study area is located in Cambridgeshire, in eastern England, centred on Monks Wood (52 $\left.24^{\prime} \mathrm{N}, 0^{\circ} 14^{\prime} \mathrm{W}\right)$ (Fig. 2). The area comprises $20 \times 20 \mathrm{~km}(40,000 \mathrm{ha})$ of intensively farmed landscape. Approximately 4\% (1,660 ha) of the area was wooded and 34 woods were deemed suitable for nuthatch occupancy, with the total area of breeding quality nuthatch territory being approximately 300 ha $(0.75 \%$ of the total landscape area) (Bellamy et al., 1998). South Rockingham Forest, about $12 \mathrm{~km}$ west of the main study area, was the most suitable area within reasonable dispersal distance capable of acting as a source of immigrant nuthatches. The landscape ranges in elevation from 0-70 $\mathrm{m}$ above sea level (ASL), with the higher ground lying to the west and forming a (slight) ridge through the middle of the study area. Several valleys are apparent, running largely north-west to south-east (Fig. 3). Monks Wood itself lies on a shallow north-facing slope.

\subsection{Model Description}

This study uses PatchMapper, an individual-based spatially explicit population model (SEPM), which combines an individual-based population simulator with a grid-based representation of the landscape. Coded in Java, for portability, a set of interactive screens control the simulation and enable user-selection of life history, dispersal and territorial parameters, as well as initial population size. Different habitat configurations and landscape management scenarios can be evaluated with a choice of landscapes, either input from a GIS or user generated. Emigration from the landscape is modelled by 'losing' an individual once it crosses the landscape edge (an absorbing boundary), which is a more realistic approach than modelling with reflective or wrapped boundaries (e.g. Pulliam et al.,1992, Tischendorf and Fahrig, 2000). Immigration is modelled by enabling individuals to enter the landscape from an edge, with immigration direction being from one of the cardinal or quadrantal compass points, or from all directions. Both immigration direction and yearly rate are userselectable. To incorporate the possible effects of landscape structure on dispersal patterns, user-selectable perceptual range and field-of-view mechanisms are integrated into the inter-patch dispersal rules, allowing the disperser to move directly to the 
nearest wood within the specified range and field-of-view. During a simulation run, the locations of individuals are superimposed on the landscape, presenting a real-time visual output to the user. PatchMapper is further described in Alderman (2005), with typical applications given in Alderman et al. (2004) and Alderman et al. (2005). For the tests in this study, and to improve the model, PatchMapper was modified to include vector-based dispersal movement and landscape-specific topographical data.

\subsection{Landscape Modelling}

The maintenance of a metapopulation within a particular landscape comprising matrix and fragmented habitat, depends in part on successful dispersal between habitat patches (Gill, 1978; Stacey and Taper, 1992; Hanski 1994; Hanski 1998). Apart from the two-dimensional spatial configuration of habitat patches, topographical features may also influence inter-patch dispersal flow patterns, particularly if vision is the main perceptual mechanism.

The size of the population within a particular patch will depend, in part, on both the size and quality of that patch. Nuthatch quality habitat is defined in terms of the area (a mutually exclusive territory) of woodland required for a pair of nuthatches to breed successfully, with territory area depending on the number and size of suitable deciduous woodland trees, namely oaks (Quercus), elms (Ulmus), beech (Fagus) and hazel (Corylus) (Enoksson and Nilsson, 1983; Nilsson, 1987; Enoksson 1990; Matthysen and Andriaensen 1998). To enable comparisons of nuthatch territories in different countries, territory area classifications have been established. These range from 'excellent' at 1 pair per hectare to 'very poor' at 1 pair per 20 hectares (Bellamy et al., 1998). It is likely that the distribution of suitable deciduous woodland trees (i.e. habitat quality) within a patch will differ, resulting in variations in species density within that patch. To increase realism, the quality of patches should therefore be modelled, in addition to their area and location, together with landscape topographical features. 
To meet these requirements, PatchMapper uses three maps for each simulation, in the form of cartographic views of the study area. Two maps model the habitat structure and habitat quality (Alderman, 2005), whilst the third models the elevation of the study area. Each map is digitised as a two-dimensional square-celled lattice, stored in a two-dimensional array. All arrays are at the same resolution (Fig. 4).

The structural map is a binary representation of habitat and matrix of the study area, modelling the two-dimensional structure of woods and matrix (Fig. 4a). The quality map is a binary representation of the suitability of the habitat for the establishment of nuthatch territories (Alderman et al., 2005) (Fig. 4b). The topographical map is a multi-value representation of elevation within the study area, defining the elevation of each modelled cell as an integer (Fig. 3). The three maps are linked via a coupled lattice structure (Alderman, 2005). During dispersal, reference is made to all three lattices to determine behaviour appropriate to habitat structure, habitat quality and elevation.

For the tests in this study, all three maps were digitised onto $200 \times 200$ squarecelled lattices, which for the area in question $(20 \times 20 \mathrm{~km})$ gave a minimum resolution of 1 ha. Modelling at this resolution meant that smaller landscape features such as hedgerows, individual trees and woods smaller than 1 ha, which may act as refuges for dispersing nuthatches, could not be modelled. This could be a problem with some landscapes, but in this case, as the study area contained few individual mature trees or rows of trees (Bellamy et al., 1998), the choice was thought an acceptable compromise between model run times and landscape resolution.

\subsection{Species Modelling}

Nuthatches were modelled by applying behavioural rules to each individual bird, with reference to the structure of the habitat and to landscape quality, an approach in which both landscape structure and species' characteristics govern population sizes and distribution (Alderman, 2005). Nuthatch life history, dispersal and territorial parameters were taken from the literature (Alderman et al., 2005). 


\subsection{Modelling Dispersal}

In the model, dispersing nuthatches search for habitat, traversing the matrix with a correlated random walk. Individuals moved a \pm 45 degree zig-zag course, centred about a main dispersal angle, with at least a modelled $100 \mathrm{~m}$ movement before each change of direction. The number of steps between directional changes was determined at random from a uniform distribution. The result was a nearly straight dispersal path; such paths are thought to maximise the chance of habitat detection over a perfectly straight one (Zollner and Lima, 1999). Dispersal into the landscape was from the landscape edge, with the main dispersal direction determined by the test, whilst dispersal from a patch within the landscape was either directly to a nearby patch if one was within perceptual range, or in a random direction.

During inter-patch dispersal, the bird moved to the first perceived nearest visible habitat cell. If more than one visible habitat cell was found at the same distance, a random choice was made to avoid any directional biasing. When a habitat patch was encountered, it was searched for suitable nuthatch habitat. If none was found, the search was resumed for a new patch. If suitable habitat was found, then depending on its occupancy status, a new territory was established, a pair formed or, if no vacancies existed, the disperser was forced to search for further suitable habitat within the wood, or to search the landscape for another wood (Alderman et al., 2005).

The basic dispersal rules carried out a two-dimensional search of the landscape. In order to model the possible effects of elevation and slope on dispersal, two additional algorithms were combined with the basic dispersal rules, namely 'elevation' and 'valley-seek', which are described as follows.

\subsection{Modelling Elevation}

The general principles behind modelling elevation are given in Fig. 5. 
With reference to Fig. 5, scanning outwards from the disperser's current position (point A), in single cell steps (representing the modelled landscape resolution), the elevation of a scan point when viewed from the disperser's current position (angle OAX) was calculated in accordance with the following expression.

$\angle O A X \stackrel{\text { def }}{=}\left\{\begin{aligned} \operatorname{Tan}^{-1}\left(\frac{\text { Distance from Current Position t o Scan Point (AY) }}{\text { Current Elevation - Scan Point Elevation (AO) }}\right) & \text { if Scan Point Elevation < Current Elevation } \\ 90^{\circ}+\operatorname{Tan}^{-1}\left(\frac{\text { Scan Point Elevation - Current Elevation (AO) }}{\text { Distance from Current Position t o Scan Point (AY) }}\right) & \text { if Scan Point Elevation } \geq \text { Current Elevation }\end{aligned}\right.$

The initial value of angle OAX is set to 0 and stored. At each scanned step the angle OAX is calculated and compared with the stored value. If the new angle is less than the previous one, then the cell is invisible and the new angle is discarded. If the new angle is greater or equal to the previous one, then the cell is visible and the new angle is stored and used as the comparison value for the next step. A flow-chart of the basic sequence is given in Fig. 6, which stops when a visible habitat cell is found, or when the perceptual range is reached (measured by the Euclidean distance from the current position to the scan point, as per distance AX in Fig. 5).

Adding an offset to the elevation of the disperser at the start of the scanning process enabled the height above the landscape to be modelled. This feature allows an individual to keep at a fixed height above the ground and also allows a wide variety of species to be modelled, from ground dwelling to high flying/migratory.

The basic elevation algorithm determines which cells are visible from a given location, but is limited to a single-cell field of view. Implicit in the concept of visual perceptual range is a species' field of view, but published coverage of this subject is sparse (Olden et al., 2004). For the tests in this study, a 90-degree field of view was employed, as a compromise between computational efficiency and ensuring that cell coverage was a factor in the resultant model behaviour. To accommodate a field of view, the basic sequence was modified, such that after each movement step a search 
of all cells within the field of view (up to the perceptual range) was carried out. The search looked at all cells, progressively fanning out from the origin (Alderman et al., 2005).

The complete algorithm records all visible cells within the individual's perceptual range, the number of which depends on the topology of the section of landscape being searched and varies dynamically as the disperser moves through the landscape.

Compare this to a two-dimensional search, where the same number of cells would be visible at all times. By determining which patches are visible, the effects of elevation can now be used to influence an individual's movement rules.

\subsection{Valley Seeking}

The elevation algorithm models all parts of the landscape that a disperser can 'see', within the (user-selected) perceptual range and field of view. Modification of the dispersal flow depends solely on the visibility of a habitat patch. It is likely, however, that other topographical features will also modify the dispersal direction. One of these may be the slope of the landscape, as is the case with african elephants' apparent preference for level ground (Wall et al., 2006) and the hill-topping behaviour of the lesser spotted fritillary (Pe'er et al., 2005). Even in sparsely wooded landscapes, it is likely that trees and bushes will still be present along watercourses. Preferring to travel under forest cover rather than cross open areas, dispersing nuthatches (and other woodland birds) may therefore follow valleys, where suitable cover is more likely to be found (Haas, 1995; Machtans et al., 1996; Belisle and Desrochers, 2002).

Analogously, ringlet butterflies (Aphantopus hyperantus) have been shown to disperse between forest glades using open rides rather than via more direct routes through dense woodland (Sutcliffe and Thomas, 1996). To incorporate this concept, a valleyseeking algorithm was added, in which a dispersing individual looks ahead for a cell lower than their current position. If a lower cell is visible, the dispersal direction is altered to the bearing from the current position to the lower cell. (The same basic elevation modelling algorithm was used, but modified to look for a lower, rather than a habitat, cell.) When selected, the valley-seek algorithm is applied at each dispersal 
step, followed by the elevation algorithm. In this way, dispersers seek-out and move towards lower ground, or down valleys. To prevent a disperser becoming trapped, at the end of a valley for example, the dispersal direction is not altered if a lower cell cannot be found.

\section{Tests}

To enable a comparison between modelling dispersal in a two-dimensional landscape (the current commonly employed modelling scenario) and the two described topographical-based algorithms, three tests were devised, called here '2D', 'elevation' and 'valley-seek'.

To act as a base comparison, the first test (2D) used the habitat and quality landscapes given in Fig. 4, modelling a two-dimensional landscape with no topographical data. To gauge the effects of elevation on the visual-perceptual abilities of dispersers, the second test (elevation) incorporated topographical data, adding the landscape given in Fig. 3, to those used for the first test. To gauge the effects of a possible topographical-based behavioural response on dispersal, the third test (valleyseek) added the valley-seeking algorithm to the set of landscapes. All tests measured the average number of pairs of nuthatches in our target wood, Monks Wood, at the centre of the test landscape, over 5,000 yearly cycles, with an immigration rate of 15 individual birds per cycle from each of the cardinal and quadrantal directions in turn. The tests were repeated for eight (modelled) perceptual ranges from 0 to $10 \mathrm{~km}$, the individual values used were as in Figs. 9 and 10. All tests used a field-of-view of 90 degrees.

\section{Results}

With eight dispersal directions, eight perceptual ranges and three test scenarios, the total number of predictions for the nuthatch population size in Monks Wood was 192. Therefore, the results were summarised as follows: 4.1.) showing the differences in 
population sizes for both of the topographical test scenarios, elevation and valleyseek, compared with those predicted by 2D (Tables 1 and 2, difference calculated as test prediction $-2 \mathrm{D}$ prediction), 4.2.) illustrating the directional sensitivity of each of the test scenarios for selected perceptual ranges (Figs. 7 and 8) and 4.3.) illustrating the effects of increasing perceptual range for each of the test scenarios for selected immigration directions (Figs. 9 and 10). Perceptual ranges of $200 \mathrm{~m}$ and $2 \mathrm{~km}$ were selected because, i) $200 \mathrm{~m}$ was representative of the known perceptual ranges of various ground and tree dwelling species (Alderman, 2005) and ii) $2 \mathrm{~km}$ corresponded to the maximum distance over which a human observer at ground level in a similar landscape was able to clearly identify woods (Alderman, pers. obs.). The actual perceptual range of the nuthatch is unknown. Immigration from the west and the south east was selected because, i) previous work (Alderman et al., 2004, Alderman, 2005) had shown that the most likely source of immigrants for the study area was a forest 12 $\mathrm{km}$ to the west and ii) immigration from the south east gave similar results for the three algorithms at the $200 \mathrm{~m}$ perceptual range (Fig. 7), but significantly different results at the $2 \mathrm{~km}$ range between all three algorithms (Fig. 8).

\subsection{Overall results}

The overall results of the tests showed that, as with previous modelling studies (Alderman et al., 2004; Alderman, 2005), the nuthatch population in Monks Wood was dependent on both perceptual range and the direction of immigration into the study area for all three test scenarios.

Both the elevation and the valley-seek algorithms showed a similar overall range of deviations from the numbers of pairs of nuthatches in Monks Wood predicted by 2D (Tables 1 and 2). The differences in predicted numbers when comparing 2D with elevation ranged from $-4.26(-29 \%)$ to $+2.84(+32 \%)$ pairs, and those comparing $2 \mathrm{D}$ with valley-seek ranged from $-5.21(-52 \%)$ to $+2.48(+35 \%)$ pairs. Both comparisons showed increasing deviations with increasing perceptual range. The 2D-elevation comparisons resulted in 8 deviations of more than \pm 1 pair for perceptual ranges $<1$ $\mathrm{km}$, but 17 such predictions for $\geq 1 \mathrm{~km}$. For the same two categories of perceptual 
range, the 2D-valley-seek comparisons resulted in 10 and 16 such deviations respectively.

Despite these similar ranges of deviations, the pattern of deviation in relation to perceptual range and immigration direction differed. For deviations of more than \pm 1 pair, as perceptual range increased, the 2D-elevation comparisons were increasingly positive, whilst the 2D-valley-seek comparisons remained predominantly negative. For a range of $1 \mathrm{~km}$ and above, of the 17 qualifying 2D-elevation comparisons, 12 were positive; of the 16 qualifying valley-seek comparisons, only 4 were positive. In contrast, for perceptual ranges below $1 \mathrm{~km}, 2$ of the 8 qualifying 2D-elevation comparisons and 2 of the 10 qualifying valley-seek comparisons were positive.

The comparison responses were dependent on both immigration direction and movement algorithm. For example, for the 2D-elevation comparisons, the northeasterly direction results peaked at +2.43 pairs at a perceptual range of $0.5 \mathrm{~km}$ and then dropped to a low of -4.26 pairs at $10 \mathrm{~km}$, whereas the southerly direction gave an essentially flat response, +0.82 to -1.00 pairs, over the whole range. For the $2 \mathrm{D}$ valley-seek comparisons, the north-easterly direction resulted in a low of -5.21 pairs at a perceptual range of $0.5 \mathrm{~km}$, rose to +0.97 pairs at $2 \mathrm{~km}$ and finally fell back to 3.78 pairs at $10 \mathrm{~km}$. As a contrast, the north-westerly direction resulted in a dip of 2.59 pairs at $0.1 \mathrm{~km}$ and rose to a maximum of +1.15 pairs at $5 \mathrm{~km}$. For some directions, and particularly for valley-seek, a small change in perceptual range could result in a relatively large change in numbers compared to $2 \mathrm{D}$, e.g. from 2.17 to -0.32 for a southerly direction and an increase in range from 0.1 to $0.2 \mathrm{~km}$, and from 0.10 to -5.21 for a north easterly direction and an increase from 0.2 to $0.5 \mathrm{~km}$.

\subsection{Directional sensitivity}

At a perceptual range of $200 \mathrm{~m}$, the $2 \mathrm{D}$ tests resulted in a population size in Monks Wood of approximately $6 \pm 0.20$ (95\% C.I.) to $8 \pm 0.22$ pairs for all immigration directions, except from the west, which predicted lower numbers of about $4 \pm 0.18$ pairs (Fig. 7). The elevation algorithm showed a similar sensitivity to immigration direction for all directions, except the north-west, where the predicted numbers were 
lower at approximately $3 \pm 0.16$ pairs, and the south-west, where numbers were higher at about $9 \pm 0.21$ pairs. The valley-seek algorithm gave a similar response to the $2 \mathrm{D}$ and elevation algorithms for immigration from the north, east, south-east, south and west, but numbers were less for the south-west (approximately $4 \pm 0.19$ pairs) and north-east (approximately $3 \pm 0.17$ pairs). With immigration from the north-west, the valley-seek and elevation algorithms predicted similar population sizes of $2 \pm 0.16$ to $3 \pm 0.17$ pairs, compared with the $2 \mathrm{D}$ algorithm's prediction of $6 \pm$ 0.2 pairs. All three algorithms gave a similar result for immigration from the north with a prediction of approximately $7 \pm 0.2$ pairs.

At a perceptual range of $2 \mathrm{~km}$, the $2 \mathrm{D}$ predicted population size for Monks Wood became directionally dependant, varying from approximately $14 \pm 0.17$ pairs for north-easterly immigration to approximately $3 \pm 0.16$ pairs for southerly immigration (Fig. 8). The response for the elevation algorithm was effectively the same as that of the $2 \mathrm{D}$ algorithm for immigration from the north, north-west, west, south-west and south. The population size in Monks Wood was greater than when using the 2D algorithm for easterly and south-easterly immigration, but less for north-easterly immigration. The response for the valley-seek algorithm differed significantly from both the $2 \mathrm{D}$ and elevation algorithms, demonstrating greater sensitivity to immigration from the north and north-east and lower sensitivity to south-easterly and westerly immigration. For this algorithm, the population size in Monks Wood was significantly greater than for the $2 \mathrm{D}$ algorithm for the northerly direction and significantly less in the westerly and south-easterly directions. All three algorithms gave a similar response for the north-westerly immigration direction.

\subsection{Perceptual range effects}

For the westerly direction, the population size predicted by the $2 \mathrm{D}$ and elevation algorithms remained effectively the same at approximately 5 pairs, up to a perceptual range of about $0.5 \mathrm{~km}$ (Fig. 9). Above this range, the $2 \mathrm{D}$ algorithm predicted a rise in population to an upper threshold of 6-7 pairs at $1 \mathrm{~km}$, and then remaining effectively the same to the upper limit of the test $(10 \mathrm{~km})$. The elevation algorithm resulted in an 
increase in population size to an upper threshold of about 8 pairs at a similar range (1 $\mathrm{km})$, declining to 6-7 pairs at the upper limit of the test.

For the south-westerly direction, the population size predicted by the $2 \mathrm{D}$ and elevation algorithms remained effectively the same at approximately 5 pairs, up to a perceptual range of about $0.2 \mathrm{~km}$ (Fig. 10). Above this range, the 2D algorithm predicted a rise in population to 8-9 pairs, decreasing to about 7 pairs at the upper limit of the test $(10 \mathrm{~km})$. The elevation algorithm resulted in an increase in population size from the $0.2 \mathrm{~km}$ perceptual range, rising to a peak of about 12 pairs at $2 \mathrm{~km}$, declining to approximately 10 pairs at the upper limit.

For both selected immigration directions, the valley-seek algorithm resulted in a threshold at approximately $0.5 \mathrm{~km}$ perceptual range, above which the predicted population size in Monks Wood decreased to a minimum at $1-2 \mathrm{~km}$, followed by a slight increase from 2-10 km (Figs. 9 and 10). Although for the westerly direction the population size was effectively constant from $0-0.5 \mathrm{~km}$, it oscillated over this range for the south-easterly direction, with a peak at $0.1 \mathrm{~km}$ and a dip at $0.2 \mathrm{~km}$. Apart from this oscillation, all three algorithms resulted in effectively similar population sizes in Monks Wood for both directions, up to $0.2-0.5 \mathrm{~km}$. Above this range, the valley-seek algorithm always predicted significantly lower population sizes. Overall, the valleyseek algorithm showed less sensitivity to perceptual range than did 2D or elevation, indicating that such behaviour in response to topography could have a powerful effect on dispersal flows through landscapes and on settlement patterns.

\section{Discussion}

The landscape used for this study was largely flat, with shallow valleys and a difference between maximum and minimum elevation of only $70 \mathrm{~m}$ and is typical of English lowlands. Despite this moderate topography, the size of the population in Monks Wood modelled using both of the three-dimensional algorithms, exhibited directional sensitivity in interaction with perceptual range, which differed from that predicted by the two-dimensional approach (Figs. 7-10). Thus, the population in 
Monks Wood was dependant on the spatial configuration of habitat patches and the topography of the landscape, both of which acted to guide dispersal towards or away from the target patch. The effect on dispersal of these landscape elements is particularly important in cases where immigration is essential in maintaining the population (Stacey and Taper, 1992; Alderman et al., 2004; Alderman, 2005).

The differences in directional sensitivity and predicted population sizes (Table 1, Figs. 7 and 8 ) between the 2D and elevation algorithms were moderate, the maximum difference in population size across all directions being $40 \%$. This suggests that in some circumstances modelling elevation could be an unwanted complication, increasing the data requirements and debugging and run-times. However, the 2Delevation comparisons that produced population differences greater than \pm 1 pair were more likely to be positive at greater perceptual ranges suggesting that a $2 \mathrm{D}$ approach could under-estimate population sizes under certain combinations of topography and perceptual range. Furthermore, that differences were apparent in such a flat landscape indicated that topography has considerable potential to influence directional dispersal decisions. In more dramatically three-dimensional landscapes, such as the Lake District (UK) or Fjordland (Norway), the distribution and orientation of hills and valleys would be expected to produce greater differences. Topography will also influence vegetation structure, e.g. riparian woodland in valley bottoms (Dmowski and Kozakiewicz, 1990; Machtans et al., 1996), which will in turn influence dispersal paths. When elevation is known to affect behaviour (e.g. Pe'er et al., 2004; Wall et al., 2006), then elevation modelling becomes an essential pre-requisite.

The valley-seek algorithm gave a distinctly different response to the $2 \mathrm{D}$ and elevation algorithms, being highly directional, even at the lower perceptual ranges (Figs. 7 and 8). Also, the much more flat response to changes in perceptual range (Figs. 9 and 10) suggested that topography was overriding perceptual range to some extent. To illustrate this, Fig. 11 shows dispersal-flow paths (Alderman et al., 2005), using valley-seek, generated by recording the accumulated paths of all dispersal within the landscape over 500 cycles, for perceptual ranges of $0.2 \mathrm{~km}$ and $2 \mathrm{~km}$ and 15 immigrants per cycle. All immigrants entered the landscape from a randomly chosen direction. Superimposing the dispersal-flow diagrams over the topographical 
landscape (see Fig. 3), revealed that topography had a greater effect on dispersal at the lower perceptual range. At $0.2 \mathrm{~km}$, dispersal closely mapped to the valleys and lower ground, with little movement over the higher ground (Fig. 11a). A low perceptual range will contain fewer patches and reduce the choice of dispersal direction. Under the valley-seek algorithm, the slope of the nearby landscape had a greater effect than perceptual range on dispersal patterns, but as perceptual range increased, the effect of topography was overcome. At higher perceptual ranges, dispensers were provided with a potentially greater field of view and could therefore 'see' directly across and along valleys. This placed a greater number of patches within range, reducing the effect of topography on dispersal flow patterns (Fig. 11b). Perceptual range is traditionally modelled with a static isotropic 360-degree field-of-view, although this is not likely to be realistic (Olden et al., 2004). The inclusion of topography results in a more realistic anisotropic perceptual range, in which not only the outer boundaries, but also the visible area within, vary dynamically as the disperser progresses through the landscape. As noted in the results, abrupt changes in numbers for some immigration directions across small changes in perceptual range (Table 2) might represent points at which dispersal paths make sudden changes, for example across a ridge into the next valley. Although a disperser can continually update its decisions as it moves, as previously unseen topography comes into view, topography will still be having a large influence on initial choice of direction, and hence also on any subsequent updating.

The dependence of the population size in Monks Wood on both perceptual range and elevation suggests that inter-patch dispersal paths will be strongly influenced by both these elements. A valley-seeking algorithm was chosen for this study, as one possible example of elevation-based behaviour. Such behaviour has not been noted in nuthatch dispersal, but was not thought unrealistic. An actual example of such behaviour was revealed in African elephants which dispersed along flatter paths if possible, avoiding moving uphill as an energy saving strategy (Wall et al., 2006). In this case, a valley-seeking algorithm would be appropriate. On the other hand, if modelling the hill-topping behaviour of the lesser spotted fritillary (Pe'er et al., 2004), a valley-avoidance algorithm would be required. 
Little empirical evidence exists regarding the visual perceptual range of individual species and such data are difficult to estimate (Wennergren et al., 1995; Lima and Zollner, 1996; Zollner, 2000). Work on small mammals has found perceptual ranges of under $10 \mathrm{~m}$ for the marsh rice rat (Oryzomys palustris) (Schooley and Branch, 2005) and 0-30 $\mathrm{m}$ for the white footed mouse (Peromyscus leucopus) (Zollner and Lima, 1997) and the root vole (Microtus oeconmus) (Andreassen et al., 1998), depending on the visual obstruction of the habitat. Perceptual ranges of 300-500 m have been found for the eastern fox squirrel (Sciurus niger) and the grey squirrel (Sciurus carolinensis) (Zollner, 2000). These are all ground or tree dwelling species and although it is intuitively likely that birds have the ability to detect landscape features at greater distances, no details on the actual perceptual ranges of birds were found in the literature. The variety of perceptual ranges amongst even this limited number of species suggests that topographical-based algorithms should be parameterised with data for the species being studied, rather than using generic values. This is further reinforced by the presence of thresholds in the results for all three algorithms used in this current study, which suggests the existence of species and landscape dependant optimal perceptual ranges.

Perceptual range has been included in several spatially explicit population models (SEPMs) in one form or another, but has rarely been explored (e.g. Saarenmaa et al., 1988; Doak et al., 1992; Turner et al., 1993; Adler and Nuernberger, 1994; Turner et al., 1994; Schippers et al., 1996). In the few that have investigated in more detail, all found that, in general, increasing perceptual range increased dispersal success within artificial landscapes (Cain, 1985; Fahrig, 1988; Zollner and Lima, 1999; Alderman, 2005; Zollner and Lima, 2005), but only two-dimensional landscapes were used. One recent (but rare) example of modelling the effects of elevation, investigated the hilltopping behaviour of the lesser spotted fritillary (Melitaea trivia) (Pe'er et al., 2005). The authors discovered that the butterfly's movements could be channelled into specific routes, or 'virtual corridors' in a modelled landscape of hills. However, despite finding a dual response to perceptual range $(3 \mathrm{~m}$ and $50 \mathrm{~m}$ ) when carrying out fieldwork on the real movement of the butterfly, their model did not include the effects of perceptual range on dispersal patterns. 
Our study is based on visual-based perceptual ability, but other forms of perception also exist such as the detection of polarised light in the pond slider turtle (Trachemys scripta) (Yeomans, 1995) and olfactory perception in the cactus bug (Chelinidea vittiger) (Schooley and Wiens, 2003). Anemotaxis has also been demonstrated in marsh rice rats (Oryzomys palustris) which search upwind or downwind, but not crosswind, for habitat that is beyond their visual perceptual range (Schooley and Branch, 2005). It is likely that these forms of perceptual ability would also be modulated by landscape topography. Depending on the size of the organism in question and its scale of movement, landscape elements may also contribute to topography, for example, hedgerows may act as guidelines for butterflies (Dover and Fry, 2001) and other organisms, and towns and cities may alter movement paths. Records of migrant passerines ringed at various sites in north Norfolk (UK), showed that birds were retrapped on the coast to the east of the town of Holkham, but not to the west. Instead, birds were later retrapped inland, suggesting that further westward movement along the coast was inhibited by the birds' reluctance to overfly the town. The subsequent movement inland may have been facilitated by the presence of hedgerows providing an alternative route (R. Baker, pers. com.).

The method of modelling elevation described in this study extends the concept of perceptual range into the third dimension, enabling the effects of elevation and elevation-based behaviour on inter-patch dispersal to be modelled. Simulation models have been proposed as key tools in the study of complex systems and the generic model presented here has the further advantage of being landscape independent (Green and Sadedin, 2005). PatchMapper's use of separate lattices for various aspects of the landscape (habitat, habitat quality and elevation) means that experiments with elevation can be undertaken by altering the elevation landscape lattice and not the elevation algorithm. (Changing the complete landscape only requires a new set of lattices [Alderman et al., 2005]). This approach offers an increase in realism over traditional two-dimensional landscape modelling, providing the promise of more accurate predictions of population sizes and dispersal paths. As described within the eco-field paradigm, the results illustrate that an organisms perception of the landscape, and hence its response to it during dispersal, is multifunctional and that topography is an essential function. Therefore, the modelling of topography and its 
related effects on movement in patchy landscapes are seen as essential ingredients in future landscape planning, assisting, for example, with the creation of additional habitat and movement corridors (Chardon et al., 2003; Sutherland et al., 2004; Watts et al., 2004).

\section{Acknowledgements}

Thanks to Ruth Swetnam for supplying the digital landscapes.

\section{References}

Acevedo, P., Delies-Mateos, M., Escudero, M.A., Vicente, J., Marco, J., Gortazar, C., 2005. Environmental constraints in the colonisation sequence of roe deer (Capreolus capreolus Linnaeus, 1758) across the Iberian Mountains, Spain. Journal of Biogeography 32, 1671-1680.

Adler, R.A., Nuernberger, B., 1994. Persistence in Patchy Irregular Landscapes.

Theoretical Population Biology 45, 41-75.

Alderman, J., McCollin, D., Hinsley, S., Bellamy, P., Picton, P., Crockett, R., 2004. Simulating population viability in fragmented woodland: nuthatch (Sitta europaea L.) population survival in a poorly wooded landscape in eastern England. In: R. Smithers (Editor), Landscape Ecology of Trees and Forests. Proceedings $12^{\text {th }}$ Annual IALE(UK) Conference. $21^{\text {st }}-24^{\text {th }}$ June 2004. IALE(UK). Royal Agricultural College, Cirencester, pp. 76-83.

Alderman, J., 2005. Conservation by Simulation. Ph.D. Thesis. School of Applied Sciences, University of Northampton, Park Campus, Northampton, UK.

Alderman, J., McCollin, D., Hinsley, S., Bellamy, P., Picton, P., Crockett, R., 2005. Modelling the effects of dispersal and landscape configuration on population distribution and viability in fragmented habitat. Landscape Ecology 20, 857-870. 
Andren, H., 1994. Effects of habitat fragmentation on birds and mammals in landscapes with different proportions of suitable habitat: a review. Oikos 71, 355-366.

Andreassen, H.P., Bjornbom, E., Carlson, R.G., Gunderson, G., Gunderson, H., 1998. Visual cues as determinants of perceptual range in root voles Microtus oeconmus. Acta Theriologica 43, 371-378.

Bellamy, P.E., Brown, N.J., Enoksson, B., Firbank, L.G., Fuller, R.J., Hinsley, S.A., Schotman, A.G.M., 1998. The influences of habitat, landscape structure and climate on local distribution patterns of the nuthatch (Sitta europaea L.). Oecologia 115, 127136.

Belisle, M., Desrochers, A., 2002. Gap-crossing decisions by forest birds: an empirical basis for parameterizing spatially-explicit, individual-based models. Landscape Ecology 17, 219-231.

Benton, T.G., Vickery, J.A., Wilson, J.D., 2003. Farmland biodiversity: is habitat heterogeneity the key? Trends in Ecology and Evolution 18, 182-188.

Cain, M.L., 1985. Random Search by Herbivorous Insects: A Simulation Model. Ecology 66, 876-888.

Chardon, J.P., Adriaensen, F., Matthysen, E., 2003. Incorporating landscape elements into a connectivity measure: a case study for the speckled wood butterfly (Pararge aegeria L.). Landscape Ecology 18, 561-573.

Dmowski, K., Kozakiewicz, M., 1990. Influence of a shrub corridor on movements of passerine birds to a lake littoral zone. Landscape Ecology 4, 99-108.

Doak, D.F., Marino, P.C., Kareiva, P.M., 1992. Spatial scale mediates the influence of habitat fragmentation on dispersal success: implications for conservation. Population Biology 41, 315-336. 
Dover, J.W., Fry, G.L.A., 2001. Experimental simulation of some visual and physical components of a hedge and the effects on butterfly behaviour in an agricultural landscape. Entomologia Experimentalis et Applicata 100, 221-233.

Enoksson, B., 1990. Autumn territories and population regulation in the nuthatch Sitta europaea: an experimental study. Journal of Animal Ecology 59, 1047-1062.

Enoksson, B., Nilsson, S.G., 1983. Territory size and population density in relation to food supply in the nuthatch Sitta europaea (Aves). Journal of Animal Ecology 52, 927-935.

Enoksson, B., Angelstam, P., Larsson, K., 1995. Deciduous forest and resident birds: the problem of fragmentation in a coniferous forest landscape. Landscape Ecology 10, 267-275.

Fahrig, L., 1988. A General Model of Populations in Patchy Habitats. Applied Mathematics and Computation 27, 53-66.

Fahrig, L., 1997. Relative effects of habitat loss and fragmentation on population extinction. Journal of Wildlife Management 61, 603-610.

Fahrig, L., 2003. Effects of habitat fragmentation on biodiversity. Annual Review Ecology and Systematic 34, 487-515.

Farina, A., Belgrano, A., 2004. The eco-field: a new paradigm for landscape ecology. Ecological Research 19, 107-110.

Gill, D.E., 1978. The metapopulation ecology of the Red-spotted Newt, Notophthalmus viridescens (Rafinesque). Ecological Monographs 48, 145-166.

Green, D.G., Sadedin, S., 2005. Interactions matter - complexity in landscapes and ecosystems. Ecological Complexity 2, 117-130. 
Gustafson, E.J., Gardner, R.H., 1996. The effect of landscape heterogeneity on the probability of patch colonisation. Ecology 77, 94-107.

Haas, C.A., 1995. Dispersal and use of corridors by birds in wooded patches on an agricultural landscape. Conservation Biology 9, 845-854.

Hanski, I., 1994. A practical model of metapopulation dynamics. Journal of Animal Ecology 63, 151-162.

Hanski, I., 1998. Metapopulation dynamics. Nature 396, 41-49.

Haydon, D., Pianka, R., 1999. Metapopulation theory, landscape models and species diversity. Ecoscience 6, 316-328.

Heinz, S.K., Strand, E., 2006. Adaptive patch searching strategies in fragmented landscapes. Evolutionary Ecology 20, 113-130.

Hinsley, S.A., Bellamy, P.E., Newton, I., Sparks, T.H., 1995. Habitat and landscape factors influencing the presence of individual bird species in woodland fragments. Journal of Avian Biology 26, 94-104.

Hinsley, S.A., Bellamy, P.E., Enoksson, B., Fry, G., Gabrielsen, L., McCollin, D., Schotman, A., 1998. Geographical and land-use influences on bird species richness in small woods in agricultural landscapes. Global Ecology and Biogeography Letters 7, 125-135.

Kindlmann, P., Aviron, S., Burel, F., 2005. When is landscape matrix important for determining animal fluxes between resource patches? Ecological Complexity 2, 150158.

Lima, S.L., Zollner, P.A., 1996. Towards a behavioural ecology of ecological landscapes. Trends in Ecology and Evolution 11, 131-134. 
Machtans, C.S., Villard, M-A., Hannon, S., 1996. Use of riparian buffer strips as movement corridors by forest birds. Conservation Biology 10, 1366-1379.

Matthysen, E., Adriaensen, F., Dhondt, A.A., 1995. Dispersal distances of nuthatches, Sitta europaea, in a highly fragmented forest habitat. Oikos 72, 375-381.

Matthysen, E., Currie, D., 1996. Habitat fragmentation reduces disperser success in juvenile nuthatches Sitta europaea: evidence from patterns of territory establishment. Ecography 19, 67-72.

Matthysen, E., Adriaensen, F., 1998. Forest size and isolation have no effect on reproductive success of eurasian nuthatches (Sitta europaea). The Auk 115, 955-963.

Mysterud, A., Langvatn, R., Yoccoz, N.G., Stenseth, N.C., 2001. Plant phenology, migrating and geographical variation in body weight of a large herbivore: the effect of a variable topography. Journal of Animal Ecology 70, 915-923.

Nilsson, S., 1987. Limitation and regulation of population density in the nuthatch Sitta europaea (Aves) breeding in natural cavities. Journal of Animal Ecology 56, 921-937

Olden, J.D., Schooley, R.L., Monroe, J.B., Poff, N.L., 2004. Context-dependent perceptual ranges and their relevance to animal movements in landscapes. Journal of Animal Ecology 73, 1190-1194.

Pain, D.J. and Pienkowski, M.W. (Editors), 1997. Farming and Birds in Europe: the Common Agricultural Policy and its Implications for Bird Conservation. Academic Press, London.

Pe'er, G., Saltz, D., Thuckle, H., Motro, U., 2004. Response to topography in a hilltopping butterfly and implications for modelling nonrandom dispersal. Animal Behaviour 68, 825-839. 
Pe'er, G., Saltz, D., Thuckle, H., Motro, U., 2005. Virtual Corridors for Conservation Management. Conservation Biology 19, 1997-2003.

Pe'er, G., Saltz, D., Thuckle, H., Motro, U., 2006. Connectivity in heterogeneous landscapes: analysing the effect of topography. Landscape Ecology 21, 47-61.

Pravosudov, V.V., 1993. Social organisation of the nuthatch (Sitta europaea). Ornis Scandinavica 24, 290-296.

Pulliam, H., Dunning, J., Liu, J., 1992. Population dynamics in complex landscapes: a case study. Ecological Applications 2, 165-177.

Ricketts, T., 2001. The Matrix Matters: Effective Isolation in Fragmented Landscapes. The American Naturalist 158, 87-99.

Roland, J., Keyghobadi, N., Fownes, S., 2000. Alpine Parnassius butterfly dispersal: effects of landscape and population size. Ecology 81, 1642-1653.

Saarenmaa, H., Stone, N.D., Folse, L.J., Packard, J.M., Grant, W.E., Makela, M.E., Coulson, R.N., 1988. An artificial intelligence modelling approach to simulating animal/habitat interactions. Ecological Modelling 44, 125-141.

Saïd, S., Servanty, S., 2005. The influence of landscape structure on female roe deer home-range size. Landscape Ecology 20, 1003-1012.

Schippers, P., Verboom, J., Knaapen, J.P., Apeldoorn, R.C., 1996. Dispersal and habitat connectivity in complex heterogeneous landscapes: an analysis with a GISbased random walk model. Ecography 19, 97-106.

Schooley, R.L., Wiens, J.A., 2003. Finding habitat patches and directional connectivity. Oikos 102, 559-570. 
Schooley, R.L., Branch, L.C., 2005. Limited perceptual range and anemotaxis in marsh rice rats Oryzomys palustris. Acta Theriologica 50, 59-66.

Stacey, P.B., Taper, M., 1992. Environmental variation and the persistence of small populations. Ecological Applications 2, 18-29.

Sutherland, W.J., Pullin, A.S., Dolman, P.M., Knight, T.M., 2004. The need for evidence-based conservation. Trends in Ecology and Evolution 19, 305-308.

Sutcliffe, O.L., Thomas, C.D., 1996. Open corridors appear to facilitate dispersal by Ringlet Butterflies (Aphantopus hyperantus) between woodland clearings.

Conservation Biology 10, 1359-1365.

Tischendorf, L., Fahrig, L., 2000. On the useage and measurement of landscape connectivity. Oikos 90, 7-19.

Tuck, J.M., Hassall, M., 2004. Foraging behaviour of Armadillidium vulgare (Isopoda: Oniscidae) in heterogeneous environments. Behaviour 141, 233-234.

Turner, M.G., Wu, Y., Romme, W.H., Wallace, L.L., 1993. A landscape simulation model of winter foraging by large ungulates. Ecological Modelling 69, 163-184.

Turner, M.G., Wu, Y., Wallace, L.L., Romme, W.H., Brenkert A., 1994. Simulating winter interactions among ungulates, vegetation and fire in northern yellowstone park. Ecological Applications 4, 472-496.

Wall, J., Douglas-Hamilton, I., Vollrath, F., 2006. Elephants avoid costly mountaineering. Current Biology 16, 527-529.

Watts, K., Griffiths, M., Quine, C., Ray, D., Humphrey, J., 2004. Towards a woodland habitat network for Wales. Contract report to the Countryside Council for Wales and the Forestry Commission, Wales. Report no. EC046CT (F13/7/369). Forest Research, Alice Holt. 
Wennergren, U., Ruckelshaus, M., Kareiva, P., 1995. The promise and limitations of spatial models in conservation biology. Oikos 74, 349-356.

Yeomans, S.R., 1995. Water-finding in adult turtles: random search or oriented behaviour. Animal Behaviour 49, 977-987.

Zollner, P.A., 2000. Comparing the landscape level perceptual abilities of forest sciurids in fragmented landscapes. Landscape Ecology 15, 523-533.

Zollner, P.A., Lima, S.L., 1999. Search strategies for landscape-level interpatch movements. Ecology 80, 1019-1030.

Zollner, P.A., Lima, S.L., 2005. Behavioural tradeoffs when dispersing across a patchy landscape. Oikos 108, 219-230. 
Perceptual Range (km)

$\begin{array}{lcccccccc}\text { Immigration } & \mathbf{0} & \mathbf{0 . 1} & \mathbf{0 . 2} & \mathbf{0 . 5} & \mathbf{1} & \mathbf{2} & \mathbf{5} & \mathbf{1 0} \\ \text { Direction } & & & & & & & & \\ \text { North } & 0.00 & -2.50 & -1.68 & 0.32 & 0.19 & -0.30 & 1.58 & 1.17 \\ \text { North East } & 0.00 & -0.60 & 0.79 & 2.43 & -0.60 & -3.64 & -3.17 & -4.26 \\ \text { East } & 0.00 & -0.26 & 0.45 & 1.08 & 0.69 & 1.77 & 0.48 & 0.63 \\ \text { South East } & 0.00 & -0.54 & 0.32 & -0.97 & 2.19 & 2.84 & 1.88 & 2.12 \\ \text { South } & 0.00 & 0.08 & 0.82 & 0.36 & 0.79 & -0.15 & -1.00 & -0.97 \\ \text { South West } & 0.00 & 0.23 & -2.09 & 0.83 & 0.49 & 1.27 & 1.24 & 0.03 \\ \text { West } & 0.00 & -0.30 & 0.78 & -0.54 & 1.38 & 1.22 & 0.26 & -0.37 \\ \text { North West } & 0.00 & -1.20 & -1.35 & 2.16 & 1.07 & 0.05 & -1.01 & -2.20\end{array}$

Table 1 - Differences between the mean predicted numbers of pairs of nuthatches in Monks Wood for the $2 \mathrm{D}$ and elevation dispersal algorithms, resulting from immigration into the landscape from the cardinal and quadrantal immigration directions over perceptual ranges of 0-10 km. Difference calculated as: elevation $-2 \mathrm{D}$. 
Perceptual Range (km)

$\begin{array}{lcccccccc}\begin{array}{l}\text { Immigration } \\ \text { Direction }\end{array} & \mathbf{0} & \mathbf{0 . 1} & \mathbf{0 . 2} & \mathbf{0 . 5} & \mathbf{1} & \mathbf{2} & \mathbf{5} & \mathbf{1 0} \\ \text { North } & 0.00 & 0.17 & -0.71 & 0.47 & 0.56 & 2.48 & 0.04 & -2.97 \\ \text { North East } & 0.00 & 0.35 & 0.10 & -5.21 & -1.19 & 0.97 & -0.50 & -3.78 \\ \text { East } & 0.00 & -1.34 & -1.72 & -0.26 & 0.56 & 0.08 & -0.68 & 0.64 \\ \text { South East } & 0.00 & -0.85 & 0.17 & -3.32 & -5.08 & -4.29 & -3.43 & -3.27 \\ \text { South } & 0.00 & 2.17 & -0.32 & -0.58 & -0.11 & 1.29 & -0.56 & 0.58 \\ \text { South West } & 0.00 & -0.36 & -3.37 & -4.90 & -1.38 & -0.77 & 0.31 & 1.70 \\ \text { West } & 0.00 & 1.99 & -0.56 & 0.13 & -2.87 & -3.33 & -3.42 & -3.17 \\ \text { North West } & 0.00 & -2.59 & -1.63 & -0.04 & 0.98 & 0.01 & 1.15 & 0.45\end{array}$

Table 2: Differences between the mean predicted numbers of pairs of nuthatches in Monks Wood for the $2 \mathrm{D}$ and valley-seek dispersal algorithms, resulting from immigration into the landscape from the cardinal and quadrantal immigration directions over perceptual ranges of 0-10 km. Difference calculated as: valley-seek $-2 \mathrm{D}$. 


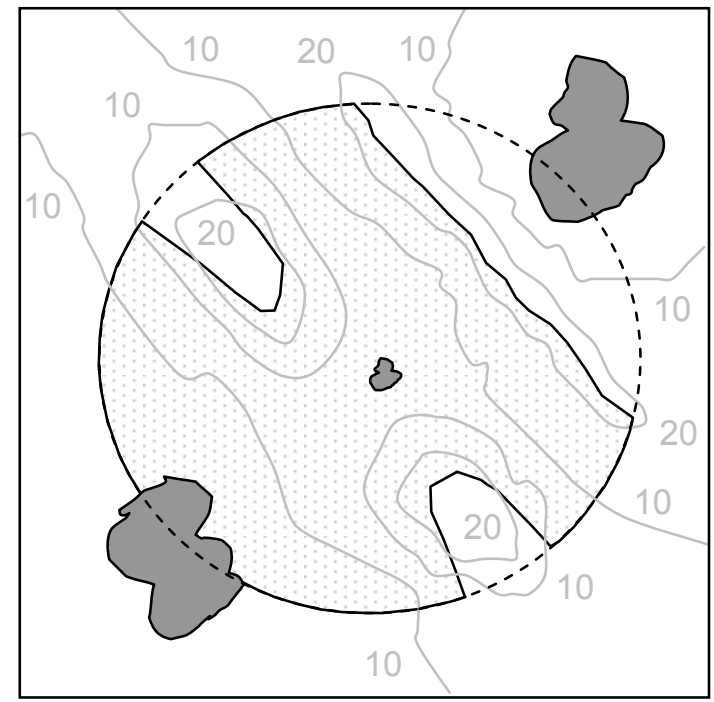

Fig. 1 - An example of the possible effects of topography on the visual perceptual range of a dispersing individual, located within the central patch. When modelling the landscape in two dimensions the whole area encompassed by the circle (the visual perceptual range) is visible, giving the individual a choice of moving to either the upper or the lower patch. When modelling the same landscape in three dimensions, the higher ground restricts the view to the shaded area, limiting the individual's choice of patch to the lower one. 


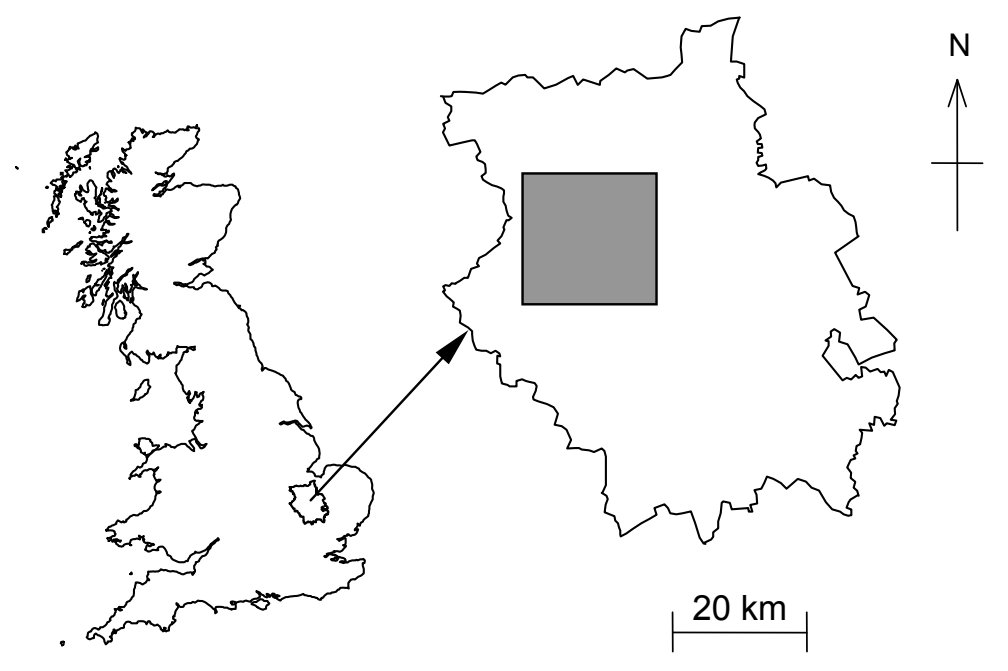

Fig. 2 - Location of the $20 \times 20 \mathrm{~km}$ study area and its position within the county of Cambridgeshire in eastern England, UK. 


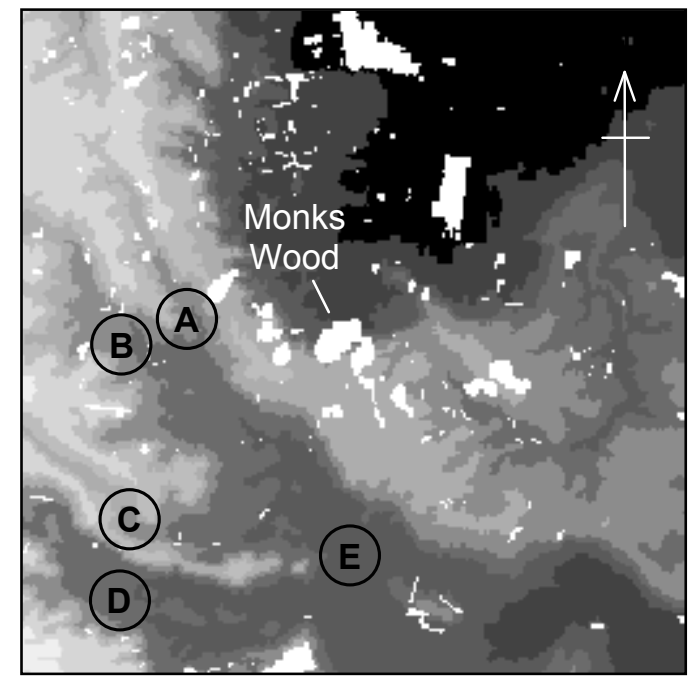

Fig. 3 - The topography of the study area, with the woodland patches (both suitable and unsuitable) superimposed in white. The topographical landscape is modelled as a multi-level representation of the landscape and integrated into the model, as described in the text. Each modelled elevation level is shown shaded, ranging from high ground (70 m ASL) shown light grey, through to black, which represents low ground ( $0 \mathrm{~m} \mathrm{ASL}$ ), in $10 \mathrm{~m}$ steps. Several valleys are present, such as those labelled A$\mathrm{E}$, which run in a roughly south-easterly direction from higher ground to the west. The target patch, Monks Wood, is located in the centre of the landscape on a shallow north-facing slope. 


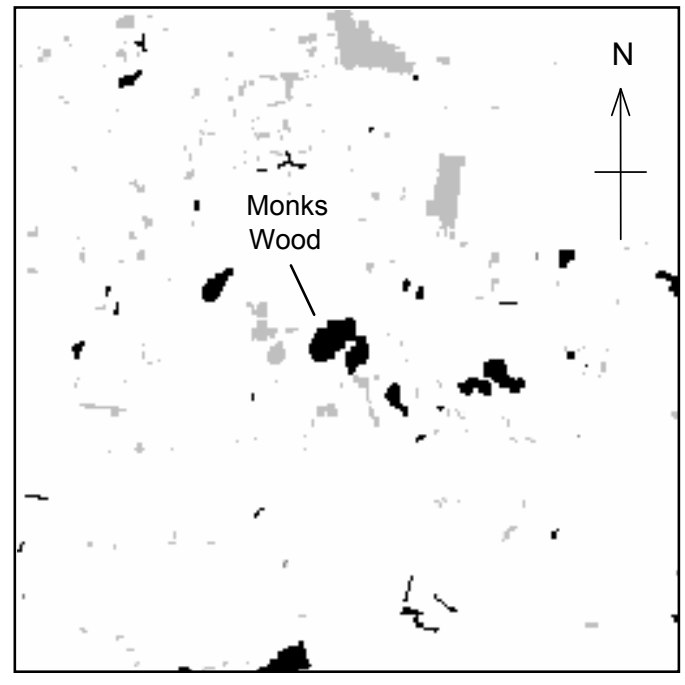

$\mathbf{a}$

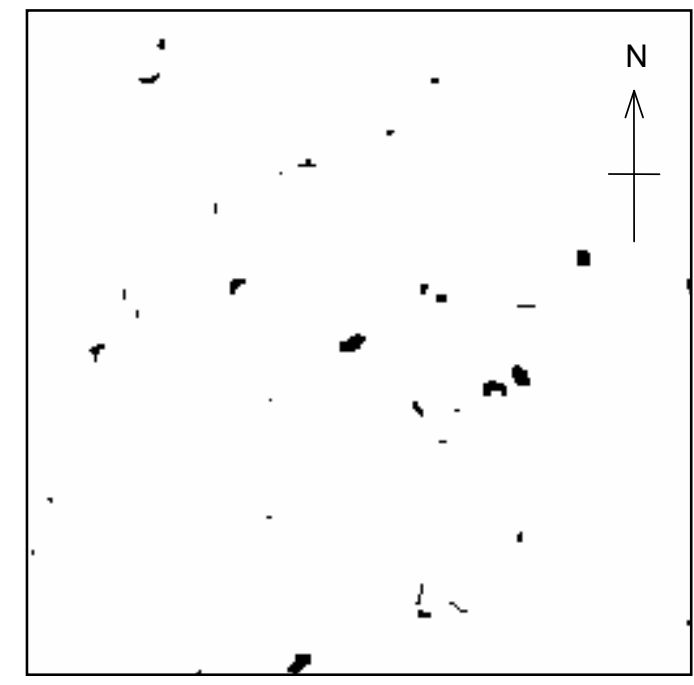

b

Fig. 4 - The structural and topographical landscapes. The structural landscape (Fig. 4a) is a binary representation of the landscape, comprising woods (potential habitat) and matrix. For illustration, woods containing suitable habitat are shown in black, with all other woods shaded light grey. The quality landscape (Fig. 4b) represents the areas of habitat of sufficient quality to contain nuthatch territories. Note that even though certain woods within the study area may have been identified as containing habitat of suitable quality for the establishment of nuthatch territories, such woods will most likely contain both suitable and unsuitable habitat (Alderman et al., 2005). 


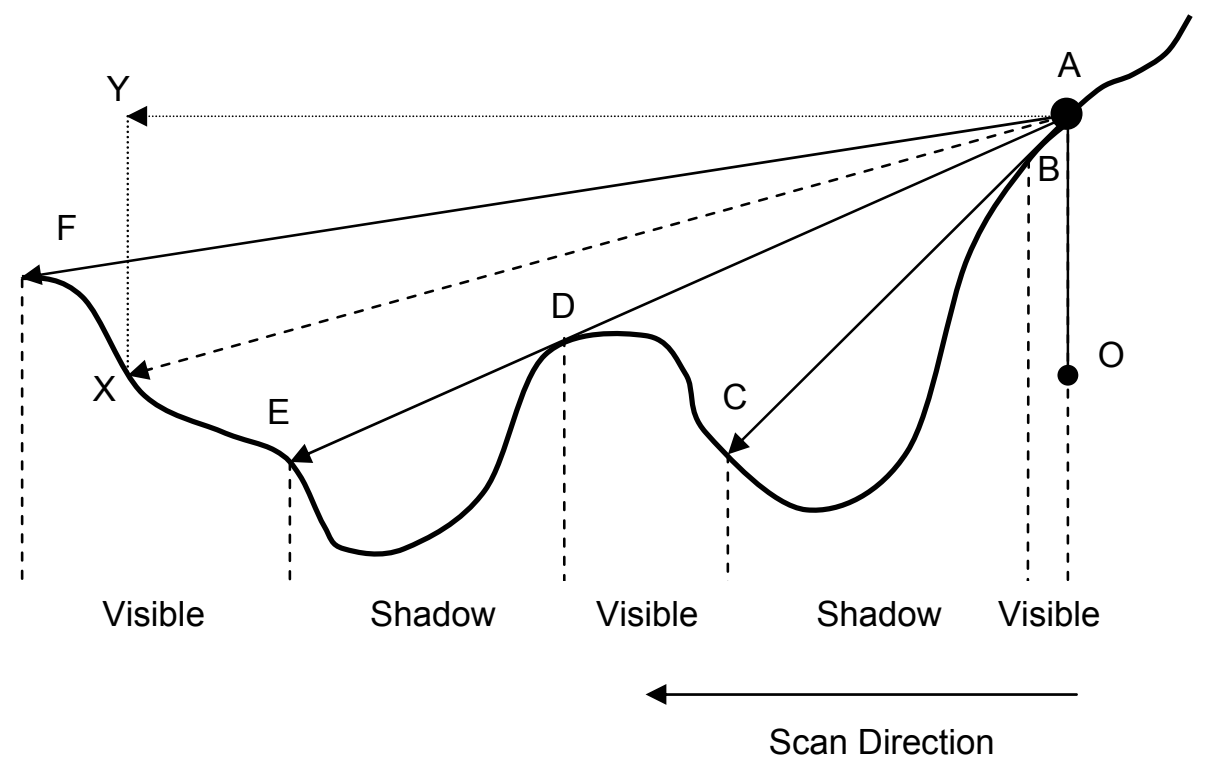

Fig. 5 - A cross-section of a landscape, demonstrating the basic principles behind elevation measurement, with points OAX, showing the measurement of the elevation angle of an example scan point, as described in the text. Point $\mathrm{A}$ is the disperser's current position and $\mathrm{X}$ is an example scan point. Distance AO represents the elevation of the current position, relative to the scan point, $\mathrm{X}$, and $\mathrm{AY}$ is the horizontal distance from the current position to $\mathrm{X}$. Distance $\mathrm{AX}$ is the Euclidean distance from the current position to the scan point, which is used to determine the perceptual range limiting value. The topography of the landscape results in certain parts of the landscape (between points B-C and D-E, labelled 'shadow'), being hidden from the disperser. The other parts (between points A-B, C$\mathrm{D}$ and E-F, labelled 'visible'), are visible. Movement is constrained to be to the left only, because all view to the right is obscured by the rising slope (to the right of A). All parts of the landscape would be visible if two-dimensional landscape modelling was employed. 


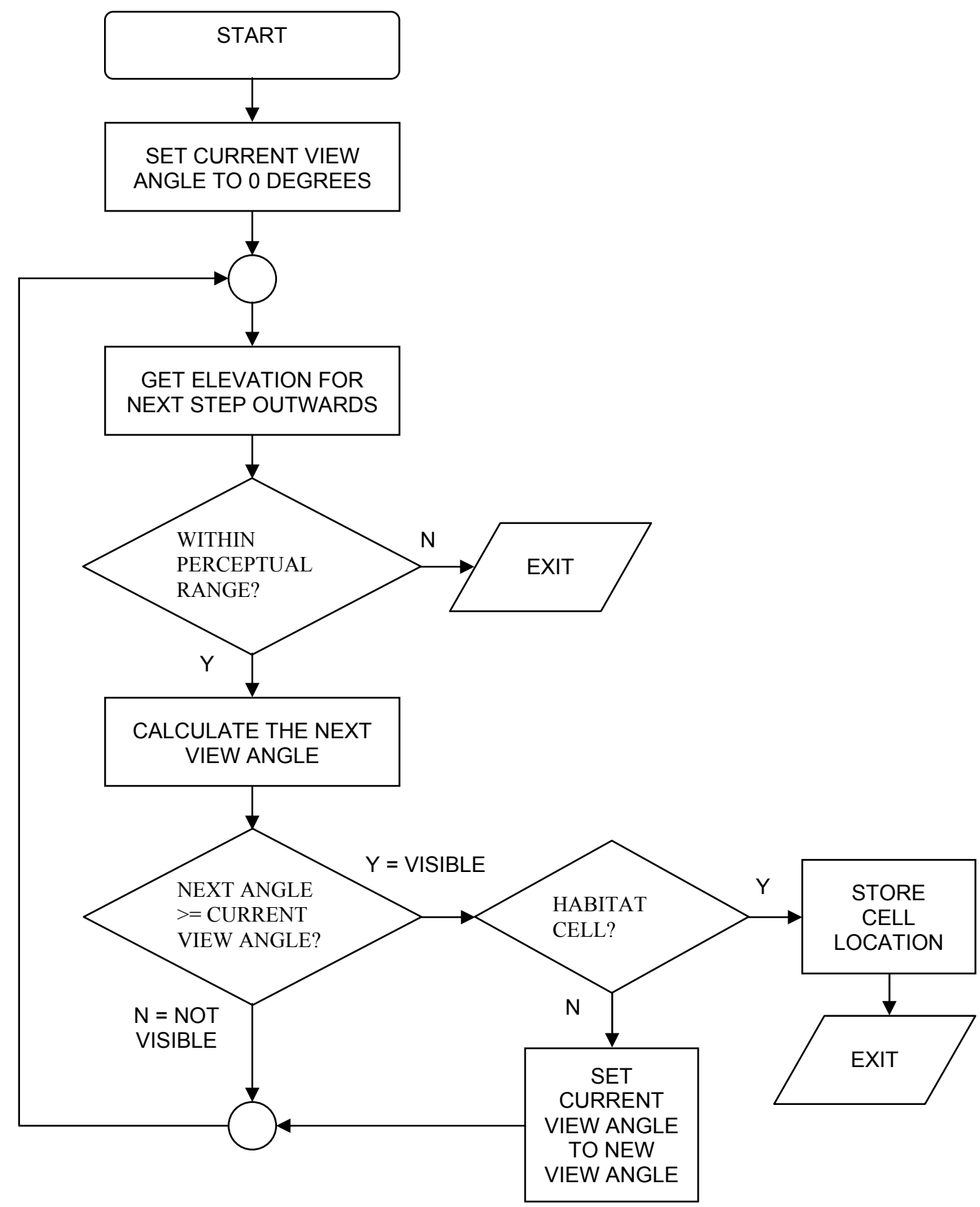

Fig. 6 - The basic elevation modelling algorithm, which stops either when the perceptual range is reached or a habitat cell is found. For the tests in this study, the algorithm was modified to accommodate a 90-degree field of view, as described in the text. 


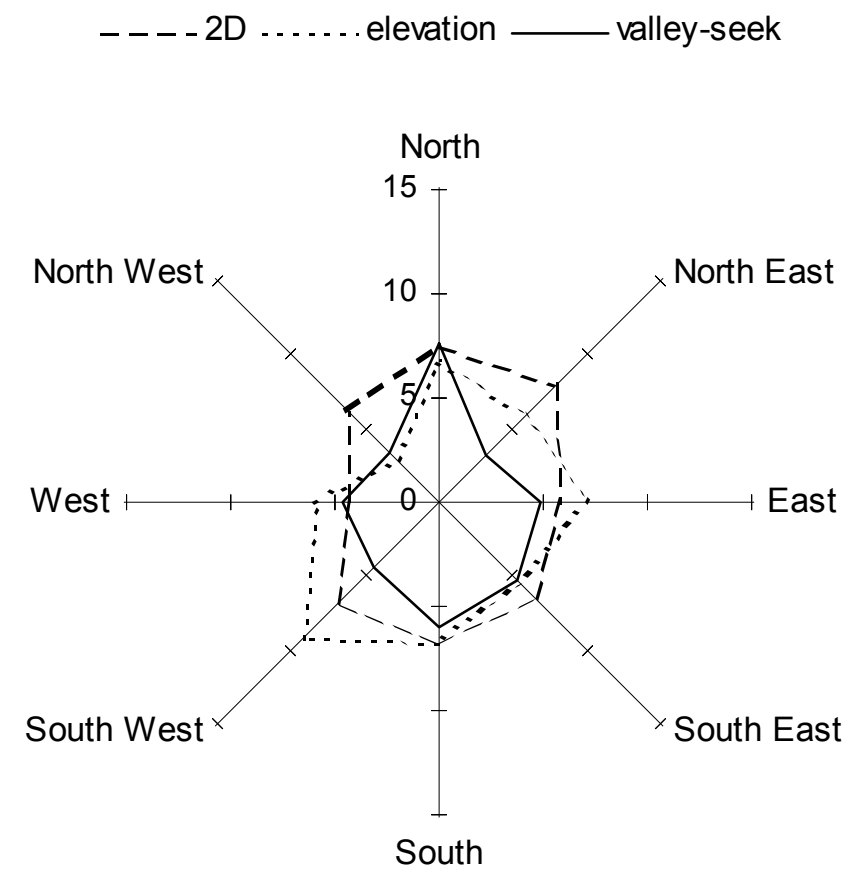

Fig. 7 - Directional sensitivity to immigration of the size of the nuthatch population in Monks Wood for a perceptual range of $200 \mathrm{~m}$ and an annual immigration rate of 15 individuals. The numerical scale gives the predicted numbers of pairs of nuthatches averaged over 5,000 yearly cycles. 
$----2 \mathrm{D} \ldots . .$. . elevation $\longrightarrow$ valley-seek

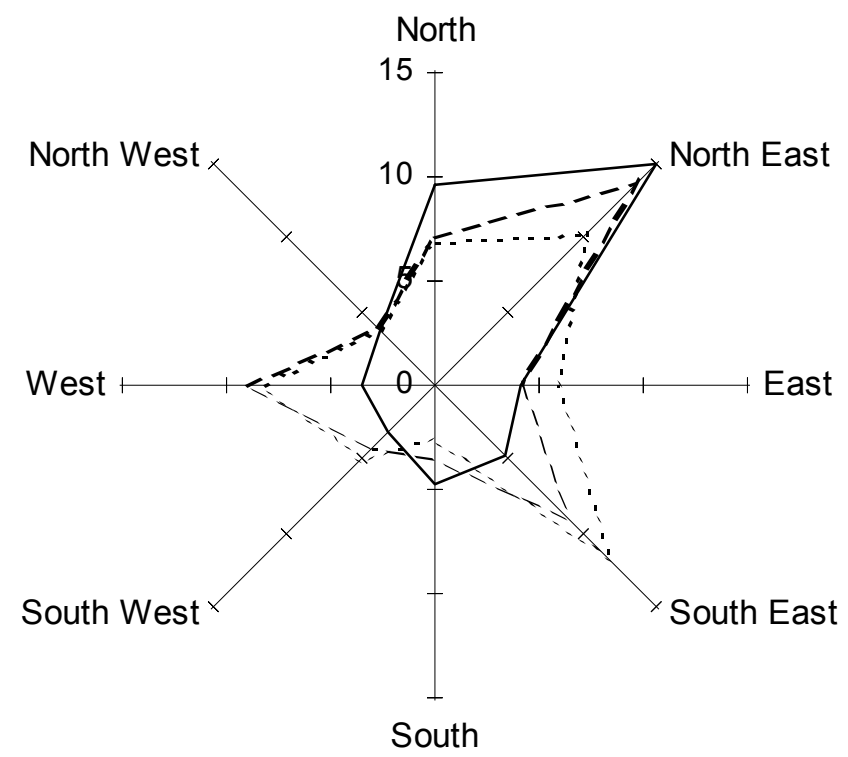

Fig. 8 - Directional sensitivity to immigration of the size of the nuthatch population in Monks Wood for a perceptual range of $2 \mathrm{~km}$ and an annual immigration rate of 15 individuals. The numerical scale gives the predicted numbers of pairs of nuthatches, averaged over 5,000 yearly cycles. 


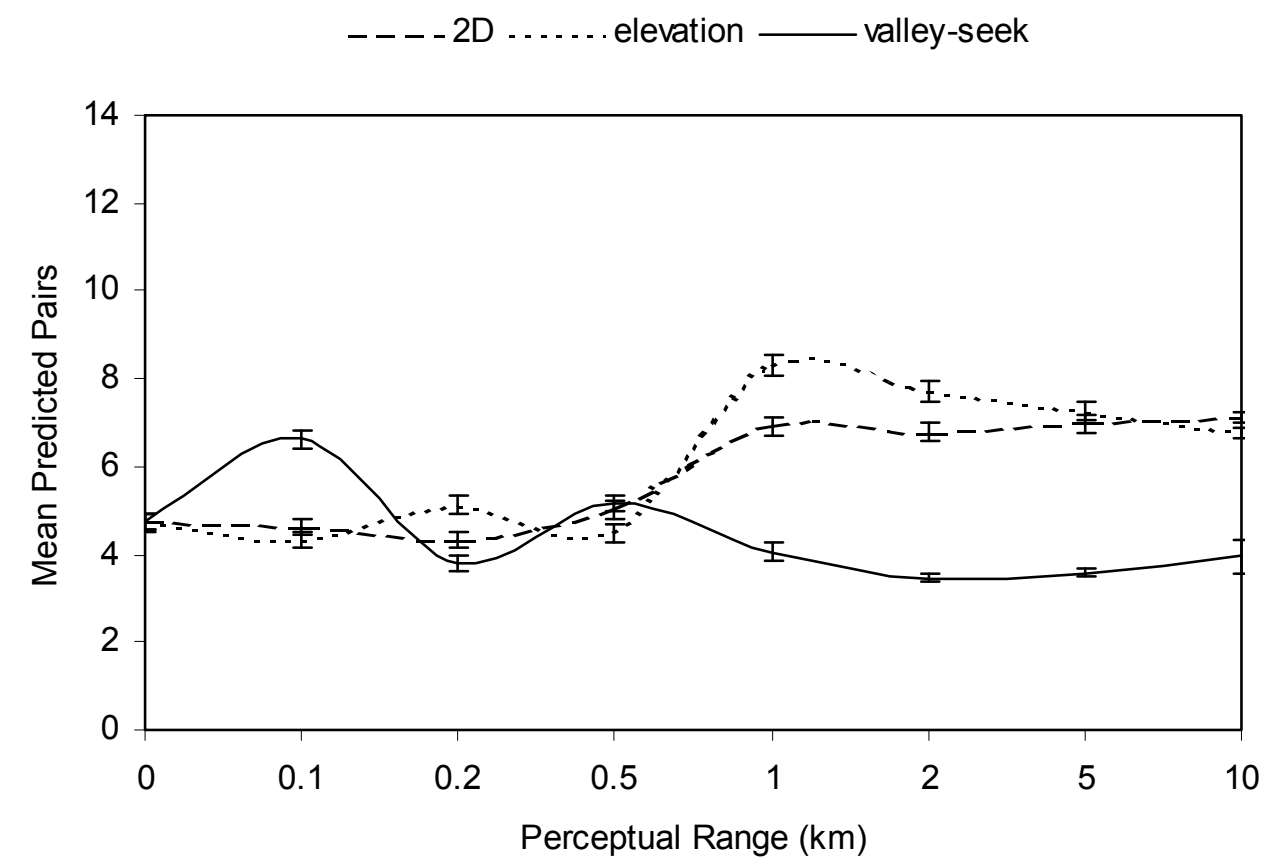

Fig. 9 - Mean predicted numbers of pairs of nuthatches in Monks Wood for a westerly immigration direction over a perceptual range of $0-10 \mathrm{~km}$ and an annual immigration rate of 15 individuals. The error bars give $95 \%$ confidence intervals. 


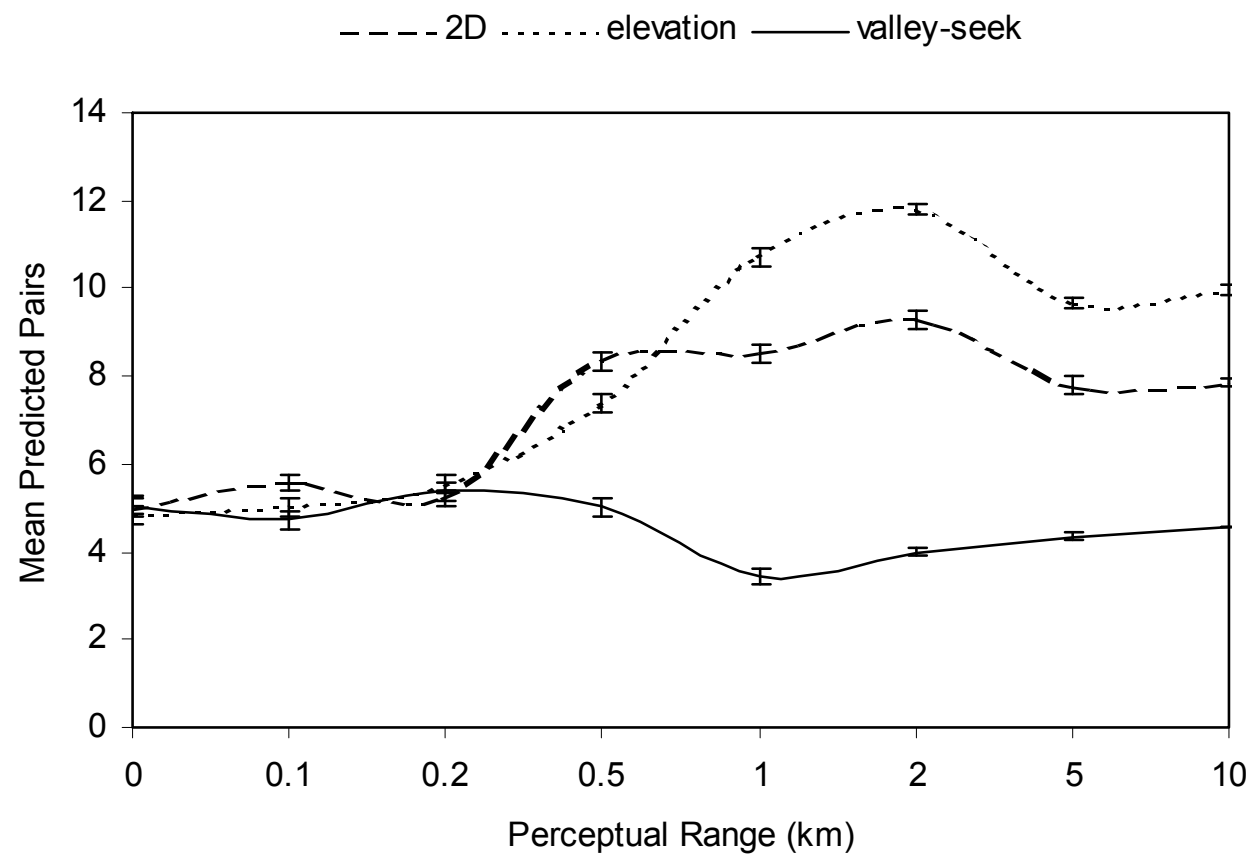

Fig. 10 - Mean predicted number of pairs of nuthatches in Monks Wood for south-easterly immigration direction over a perceptual range of $0-10 \mathrm{~km}$ and an annual immigration rate of 15 individuals. The error bars give $95 \%$ confidence intervals. 

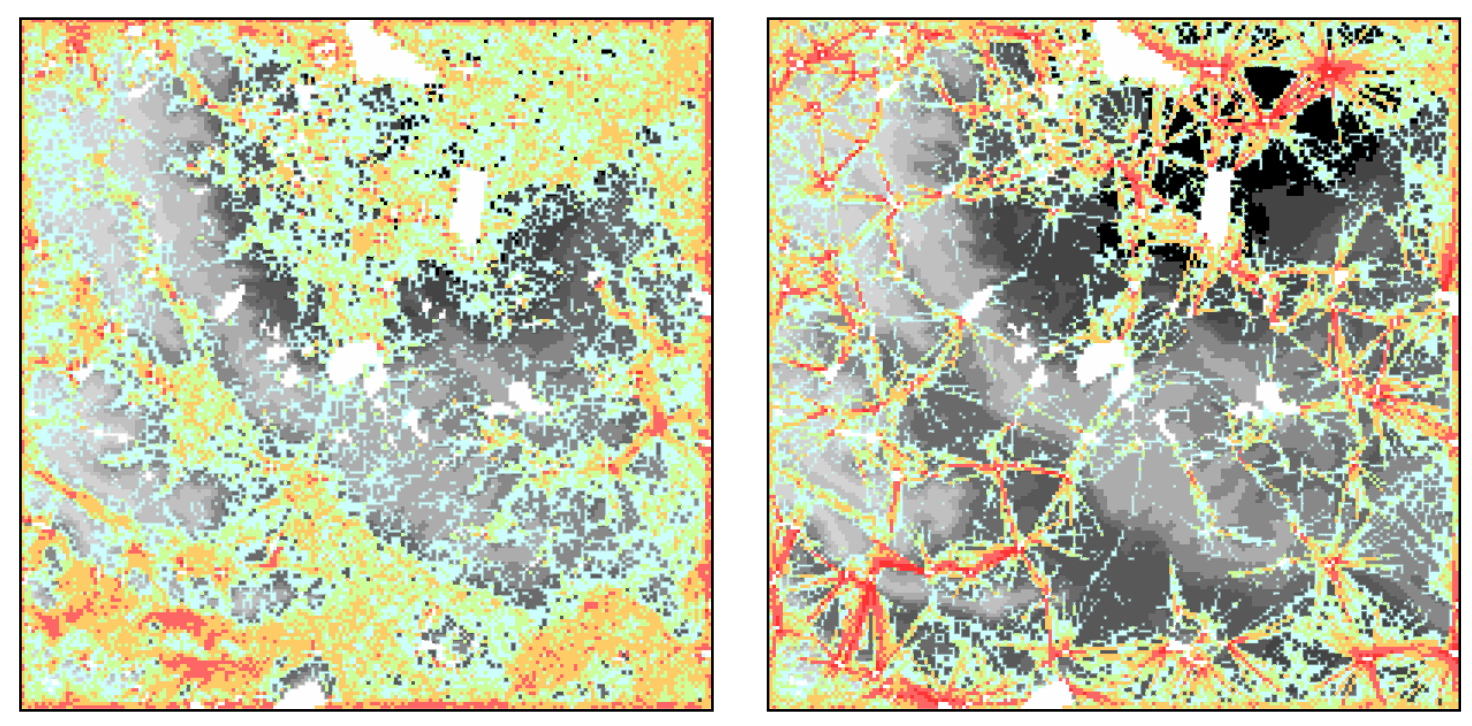

Fig. 11 - Dispersal-flow diagrams of the study landscape, showing the inter-patch dispersal paths for perceptual ranges of $0.2 \mathrm{~km}$ (11a) and $2 \mathrm{~km}$ (11b) using the valley-seek algorithm. Dispersal density is recorded for 15 individuals (blue), 16-20 (green), 21-50 (orange) and 50+ (red). The lower flow densities (of 10 individuals and less) have been removed, revealing portions of the underlying topography to give some idea of its influence on dispersal patterns. 